Veselý J., Horný L., Chlup H., Adámek T., Krajíček M., Žitný R. (2015) Constitutive Modeling of Human saphenous veins at overloading Pressures. Journal of the Mechanical Behavior of Biomedical Materials, in press. DOI: 10.1016/j.jmbbm.2015.01.023 Publisher link http://dx.doi.org/10.1016/j.jmbbm.2015.01.023

\title{
Constitutive Modeling of Human Saphenous Veins at Overloading Pressures
}

\author{
J. Veselýa , L. Hornýa ${ }^{\mathrm{a}}$ H. Chlup ${ }^{\mathrm{a}}$, T. Adámek $^{\mathrm{b}}$, M. Krajíček $^{\mathrm{c}}$, R. Žitnýa \\ ${ }^{a}$ Faculty of Mechanical Engineering, Czech Technical University in Prague, Technicka 4, 16607 Prague, Czech \\ Republic \\ b Third Faculty of Medicine, Charles University in Prague, Ruska 87, 10000 Prague, Czech Republic \\ ${ }^{c}$ General University Hospital in Prague, U Nemocnice 2, 12808 Prague, Czech Republic
}

\section{Corresponding author:}

Jan Veselý

Faculty of Mechanical Engineering, Czech Technical University in Prague, Technicka 4, 16607 Prague, Czech Republic

Tel.: +420224352690

Fax.: +420233322482

E-mail address: jan.vesely1@fs.cvut.cz

\begin{abstract}
In the present study, inflation tests with free axial extension of 15 human vena saphena magna were conducted ex vivo to obtain data suitable for multi-axial constitutive modeling at overloading conditions (pressures up to approximately $15 \mathrm{kPa}$ ). Subsequently the data were fitted with a hyperelastic, nonlinear and anisotropic constitutive model based on the theory of the closed thickwalled tube. It was observed that initial highly deformable behavior (up to approximately $2.5 \mathrm{kPa}$ ) in the pressure-circumferential stretch response is followed by progressive large strain stiffening. Contrary to that, samples were much stiffer in longitudinal direction, where the observed stretches were in the range $0.98-1.03$ during the entire pressurization in most cases. The effect of possible residual stress was evaluated in a simulation of the intramural stress distribution with the opening angle prescribed to $0^{\circ}, 10^{\circ}, 20^{\circ}, 30^{\circ}, 40^{\circ}$, and $50^{\circ}$. The result suggests that the optimal opening angle making the stress distribution through the wall thickness uniform is about $40^{\circ}$. The material parameters presented here are suitable for use in mechanobiological simulations describing the adaptation of the autologous vein wall after bypass surgery.
\end{abstract}

Keywords: anisotropy; bypass graft; collagen; constitutive model; saphenous vein; strain energy density. 
Veselý J., Horný L., Chlup H., Adámek T., Krajíček M., Žitný R. (2015) Constitutive Modeling of Human saphenous veins at overloading Pressures. Journal of the Mechanical Behavior of Biomedical Materials, in press. DOI: 10.1016/j.jmbbm.2015.01.023 Publisher link http://dx.doi.org/10.1016/j.jmbbm.2015.01.023

\section{Introduction}

Autologous saphenous vein grafts are used in both coronary and peripheral bypass surgery as the gold standard (Perera et al., 2004; Canver, 1995). Their properties are, however, optimized for a mechanical environment very different from arterial conditions. Immediately after the surgery, remodeling processes are triggered and the vein adapts to the elevated blood pressure, flow rate and oscillatory wall shear stress. As an undesirable effect of the changed conditions, the patency of the graft may be substantially compromised by an intimal hyperplasia or thrombosis (Fitzgibbon et al., 1996; Hwang et al., 2012).

Much work is now being done to deepen our knowledge of the mechanobiology of graft remodeling, but this process is still not completely understood (Tran-Son-Tay et al., 2008; Hwang et al., 2012; Hwang et al., 2013; Sassani et al., 2013). The adaptation to the changed conditions leads not only to a change in the diameter and thickness of the graft wall, but also to a changed internal structure and thus a change in the constitutive equation expressing the mutual relation between stress and strain (Hwang et al., 2012). Moreover, not only the wall shear stress, but also changed intramural stresses initiate the remodeling (Eberth et al., 2011; Humphrey et al., 2009). Besides the overall effect of elevated blood pressure, there are local stress concentrations in artery-graft anastomoses caused either by the specific geometry of the anastomosis or by a general compliance mismatch (Ballyk et al., 1998; Cacho et al., 2007).

In contrast to the work done on arteries, there have been only a few papers describing the multiaxial mechanical response of veins within the framework of nonlinear elasticity (Desch and Weizsäcker, 2007; Cacho et al., 2007; McGilvray et al., 2010; Sokolis, 2013; Zhao et al. 2007). Probably, the most comprehensive study of mechanical properties of saphenous veins has been provided by Donovan et al. (1990). They however used a uniaxial tensile test, which imposes certain limitations on their data when used to construct 3D constitutive equations of a nonlinear anisotropic material (Holzapfel, 2006). There are also papers reporting pressure-diameter relationships, but without arriving at the constitutive equations (Stooker et al., 2003; Wesly et al., 1975). 
Veselý J., Horný L., Chlup H., Adámek T., Krajíček M., Žitný R. (2015) Constitutive Modeling of Human saphenous veins at overloading Pressures. Journal of the Mechanical Behavior of Biomedical Materials, in press. DOI: 10.1016/j.jmbbm.2015.01.023 Publisher link http://dx.doi.org/10.1016/j.jmbbm.2015.01.023

The main goal of our study is to find constitutive equations for the multi-axial state of stress suitable for describing the passive nonlinear anisotropic mechanical behavior of human vena saphena magna. Our approach is based on the strain energy density function suggested by Holzapfel et al. (2000). Experimental data were obtained in ex vivo inflation tests (with free axial extension) conducted with samples obtained from fifteen donors.

\section{Material and Methods}

\subsection{Material}

Human great saphenous veins for inflation-extension tests were collected either during coronary-artery bypass surgery conducted at the General University Hospital in Prague (obtained with informed consent) or during autopsies conducted at the Department of Forensic Medicine of the Third Faculty of Medicine of Charles University in Prague within 24 hours after death. The experimental protocol was approved by the institutional Ethical Committees. Collected veins were placed in the physiological solution and tested in three hours after excision. The segment of the vein without side branches and of minimal length $40 \mathrm{~mm}$ was cut from a body. Surrounding connective tissue and fat were removed from the graft material before mechanical testing. Only the veins with no substantial deviation from circular cylindrical geometry were included into the study. Prior to the mechanical testing, two rings were cut out from the tissue at both ends, and the mean reference dimensions of the samples (external radius, thickness) were determined by means of image analysis of digital photographs (Nis-Elements, Nikon Instruments Inc., NY, USA).

\subsection{Inflation-extension test}

Each specimen was marked with a black liquid eye-liner, cannulated at one end and hung vertically in the experimental setup (Fig. 1). The experimental protocol consisted of four pre-cycles to stabilize the mechanical response (preconditioning), and a fifth cycle was used in the data analysis. Pressurization was performed in the range from 0 up to $\approx 15 \mathrm{kPa}$ using a motorized syringe (Standa Ltd, Vilnius, 
Veselý J., Horný L., Chlup H., Adámek T., Krajíček M., Žitný R. (2015) Constitutive Modeling of Human saphenous veins at overloading Pressures. Journal of the Mechanical Behavior of Biomedical Materials, in press. DOI: 10.1016/j.jmbbm.2015.01.023 Publisher link http://dx.doi.org/10.1016/j.jmbbm.2015.01.023

Lithuania). The intraluminal pressure was monitored by pressure transducer (Cressto s.r.o, Czech Republic). The deformed geometry was recorded by a CCD camera (Dantec Dynamics, Skovlunde, Denmark). In the data post processing, changes in the length between the black marks (Fig. 1) and average changes in the silhouette (also between the marks to avoid end effects) were determined by the edge detection algorithm in Matlab (MathWorks, MA, USA). They were used to compute axial stretch ratio $\lambda_{z}$ and circumferential stretch ratio at the outer radius $\lambda_{\theta}\left(r_{o}\right)$. The experiments were performed at room temperature $\left(22^{\circ} \mathrm{C}\right)$.

\subsection{Theoretical framework}

\subsubsection{Kinematics}

The vein was considered to be a homogeneous, incompressible cylindrical thick-walled tube. The kinematics of the experiment was modeled as simultaneous inflation and extension, in which the material particle located in the reference (stress free) configuration in the position $X=(R, \Theta, Z)$ is mapped by the deformation into the position $x=(r, \theta, z)$ in the current configuration, according to equation (1).

$r=r(R) \quad \theta=\Theta \quad z=\lambda_{z} Z$

The situation is depicted in Fig. 2. Here $R_{o}$ and $R_{i}$ respectively denote the outer and inner radius in the reference configuration $\left(R_{i} \leq R \leq R_{o}\right)$ and $r_{o}$ and $r_{i}$ in the deformed configuration $\left(r_{i} \leq r \leq r_{o}\right)$. By analogy, $H$ and $h$ denote thickness of the tube and $L(0 \leq Z \leq L)$ and $l(0 \leq z \leq l)$ denote its length measured between the marks.

The deformation gradient $\mathbf{F}=\partial \boldsymbol{x} / \partial \boldsymbol{X}$ is then described by equation (2). Here the longitudinal stretch ratio was considered to be uniform. The assumption of incompressibility is expressed via the kinematical constraint $\operatorname{det} \mathbf{F}=1$, which allows us to write $\lambda_{r}$ also as $\lambda_{r}=1 /\left(\lambda_{\theta} \lambda_{z}\right)$. 
Veselý J., Horný L., Chlup H., Adámek T., Krajíček M., Žitný R. (2015) Constitutive Modeling of Human saphenous veins at overloading Pressures. Journal of the Mechanical Behavior of Biomedical Materials, in press. DOI: 10.1016/j.jmbbm.2015.01.023 Publisher link http://dx.doi.org/10.1016/j.jmbbm.2015.01.023

$\mathbf{F}=\left(\begin{array}{ccc}\lambda_{r}(r) & 0 & 0 \\ 0 & \lambda_{\theta}(r) & 0 \\ 0 & 0 & \lambda_{z}\end{array}\right)=\left(\begin{array}{ccc}\frac{\partial r}{\partial R} & 0 & 0 \\ 0 & \frac{r}{R} & 0 \\ 0 & 0 & \frac{l}{L}\end{array}\right)$

It is useful to express the incompressibility condition by means of the radius and the length: $\pi L\left(R_{o}^{2}-R_{i}^{2}\right)=\pi l\left(r_{o}^{2}-r_{i}^{2}\right)$. This was used to compute the inner radius during the deformation. From here, substituting $R_{i}$ by $R$ and $r_{i}$ by $r$, we also arrive at $R=R(r)$ required in $\lambda_{\alpha}(r)$ expression.

\subsubsection{Constitutive model}

The material of vena saphena magna was considered to be an anisotropic hyperelastic continuum characterized by the strain energy density function $W$ proposed by Holzapfel et al. (2000). The anisotropy arises from two families of preferred directions (interpreted as the orientation of the collagen fibers) symmetrically disposed with respect to the circumferential axis. This is expressed mathematically in equation (3).

$W=W_{\text {isotropic }}+W_{\text {anisotropic }}=\frac{\mu}{2}\left(I_{1}-3\right)+\frac{k_{1}}{2 k_{2}} \sum_{i=4,6}\left\{\exp \left[k_{2}\left(I_{i}-1\right)^{2}\right]-1\right\}$

This expression consists of a neo-Hooke term with a stress-like material parameter $\mu>0 . I_{1}$ is the first invariant of the right Cauchy-Green strain tensor $\mathbf{C}, \mathbf{C}=\mathbf{F}^{T} \mathbf{F}$. The specific mathematical expression of $I_{1}$ is in (4). The neo-Hooke term represents the energy stored in the process of a deformation in the whole non-collagenous matter (elastin, smooth muscle cells, proteoglycans) of the vein wall.

$I_{1}=\lambda_{r}^{2}+\lambda_{\theta}^{2}+\lambda_{z}^{2}$

Significant large strain stiffening of the soft tissues is ascribed to the collagen fibrils, and is modeled in (3) by an exponential function with stress-like parameter $k_{1}>0$ and dimensionless $k_{2}>0$. $I_{4}$ and $I_{6}$ are additional strain invariants arising from the existence of two preferred directions. In our case (no shear strain, and collagen fibrils creating helixes in the surfaces characterized by 
Veselý J., Horný L., Chlup H., Adámek T., Krajíček M., Žitný R. (2015) Constitutive Modeling of Human saphenous veins at overloading Pressures. Journal of the Mechanical Behavior of Biomedical Materials, in press. DOI: 10.1016/j.jmbbm.2015.01.023 Publisher link http://dx.doi.org/10.1016/j.jmbbm.2015.01.023

$R=$ constant), they can be expressed by equation (5). Here $\beta$ denotes the inclination from the circumferential axis (the second helix runs with angle $-\beta$, but due to the symmetry only equation (5) is necessary).

$$
I_{4}=I_{6}=\lambda_{\theta}^{2} \cos ^{2} \beta+\lambda_{z}^{2} \sin ^{2} \beta
$$

Finally, the constitutive equation for an incompressible hyperelastic material can be written in the form of (6). Here $\boldsymbol{\sigma}$ denotes the Cauchy stress tensor and $p$ is an undetermined multiplier induced by incompressibility constraint.

$$
\boldsymbol{\sigma}=2 \mathbf{F} \frac{\partial W}{\partial \mathbf{C}} \mathbf{F}^{T}-\mathbf{I} p
$$

\subsubsection{Thick-walled tube model}

Let us denote as $\hat{W}$ the strain energy density function (3) with eliminated explicit dependence on $\lambda_{r}$ by substituting $\lambda_{r}=1 /\left(\lambda_{\theta} \lambda_{z}\right)$. Considering the boundary conditions $\sigma_{r r}\left(r_{i}\right)=-P$ and $\sigma_{r r}\left(r_{o}\right)=0$, the equilibrium equations in the radial and axial direction have the form (7) and (8), respectively. Here $P$ denotes internal pressure and $F_{\text {red }}$ is the reduced axial (prestretching) force acting on the closed end of the tube additionally to the force generated by the pressure acting on the end (Horny et al., 2014a; Horny et al., 2014b; Matsumuto and Hayashi, 1996).

$$
\begin{aligned}
& P=\int_{r_{i}}^{r_{\theta}} \lambda_{\theta} \frac{\partial \hat{W}}{\partial \lambda_{\theta}} \frac{d r}{r} \\
& F_{\text {red }}=\pi \int_{r_{i}}^{r_{\theta}}\left(2 \lambda_{z} \frac{\partial \hat{W}}{\partial \lambda_{z}}-\lambda_{\theta} \frac{\partial \hat{W}}{\partial \lambda_{\theta}}\right) r d r
\end{aligned}
$$

\subsubsection{Determination of the material parameters}

The material parameters $\left(\mu, k_{1}, k_{2}, \beta\right)$ of the constitutive model were determined by fitting model predictions based on (7) and (8) to the experimental data. The objective function $Q$ (9) was minimized in Maple (Maplesoft, Waterloo, Canada). $P^{\text {mod }}$ and $P^{\exp }$ in (9) denote the internal pressure predicted by 
Veselý J., Horný L., Chlup H., Adámek T., Krajíček M., Žitný R. (2015) Constitutive Modeling of Human saphenous veins at overloading Pressures. Journal of the Mechanical Behavior of Biomedical Materials, in press. DOI: 10.1016/j.jmbbm.2015.01.023 Publisher link http://dx.doi.org/10.1016/j.jmbbm.2015.01.023

(7) and measured experimentally, respectively. The same denotation applies for axial force $F_{\text {red. }}$ Neglecting the small weight of the tube's lower plug $(\approx 5 \mathrm{~g}), F_{\text {red }}{ }^{\exp }$ was considered to be $0 . w_{p}$ and $w_{F}$ are weight factors. $n$ is the number of observation points.

$Q=\sum_{j=1}^{n}\left\{\left[w_{p}\left(P_{j}^{\text {mod }}-P_{j}^{e x p}\right)\right]^{2}+\left[w_{F}\left(F_{\text {redj }}^{\text {mod }}-F_{\text {redj }}^{\text {exp }}\right)\right]^{2}\right\}$

The regression analysis was divided into two steps. The isotropic response of the non-collagenous component described in (3) by the neo-Hooke term was determined in the first step via linear regression with experimental data restricted to the interval from 0 to approx. $0.8 \mathrm{kPa}$ for all specimens. Subsequently, all the data were fitted by the model with $\mu$ held fixed from the previous step. This approach ensures that the model will predict the behavior correctly at small strains (otherwise it may be biased by progressive large strain stiffening of the collagen). Finally, the quality of the regression was evaluated by normalized root mean square error $\operatorname{RMSE}(P)$ defined as

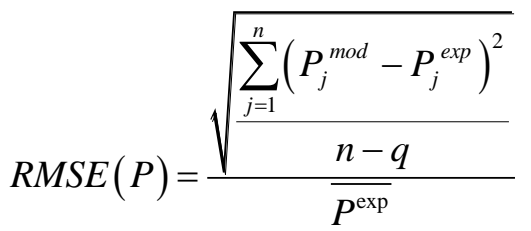

where $q$ is the number of parameters in constitutive model and $\overline{P^{\mathrm{exp}}}$ is the mean of experimental pressures for each sample.

\subsubsection{Opening angle estimation}

To provide qualified estimate of how large the residual strain in the venous wall could be, we computed the intramural distribution of the circumferential and axial stress in one representative case (donor M60a) for opening angles $\alpha=0^{\circ}, \alpha=10^{\circ}, \alpha=20^{\circ}, \alpha=30^{\circ}, \alpha=40^{\circ}$ and $\alpha=50^{\circ}$. The method is based on the assumption that the opened up geometry is modeled as a circular sector, as explained in detail for instance in Chuong and Fung (1986), Rachev and Greenwald (2002), Holzapfel et al. (2000), Horny et al. (2014a,b). Adopted approach modifies Eq. (1b) and incompressibility condition 
Veselý J., Horný L., Chlup H., Adámek T., Krajíček M., Žitný R. (2015) Constitutive Modeling of Human saphenous veins at overloading Pressures. Journal of the Mechanical Behavior of Biomedical Materials, in press. DOI: 10.1016/j.jmbbm.2015.01.023 Publisher link http://dx.doi.org/10.1016/j.jmbbm.2015.01.023

mentioned in 2.3.1 to the form (11a) and (11b), respectively. Here $\rho_{o}$ and $\rho_{i}$ denote outer and inner radius of opened up circular sector.

$$
\theta=\frac{\pi}{\pi-\alpha} \Theta \quad \pi l\left(r_{o}^{2}-r_{i}^{2}\right)=(\pi-\alpha) L\left(\rho_{o}^{2}-\rho_{i}^{2}\right)
$$

Values of the intramural stress gradient for $P=2.3 \mathrm{kPa}$ (representative venous pressure) and $P=$ $13.3 \mathrm{kPa}$ (representative arterial pressure) were computed according equation (12). We assumed that the optimal opening angle homogenizes the stress distribution across the wall thickness $\left(S R_{k}^{P}=1\right)$.

$$
S R_{k}^{P}=\frac{\sigma_{k k}\left(r_{i}\right)}{\sigma_{k k}\left(r_{o}\right)} \quad \text { for } k=\theta, z \text { and } P=2.3 k P a, 13.3 k P a
$$

\section{Results}

The data collected in the experiments are summarized in Table 1. Column Mean $\left(\left|F_{\text {red }}{ }^{\text {mod }}\right|\right)$ shows how accurately was the axial force predicted by the model $\left(F_{\text {red }}{ }^{\text {exp }}=0\right)$. Eleven samples of human saphenous vein were collected during surgery (mean \pm SD; age $55 \pm 15 ; 7$ male and 4 female; 3 donors with varicose disease) and four in autopsy (age $65 \pm 5 ; 3$ male and 1 female; one with varicose disease). Fig. 3 shows the loading part of the fifth inflation-extension cycle to which the constitutive models were fitted. Model predictions were obtained by substituting the estimated parameters into the system (7) and (8), and are depicted by continuous curves (donors with varicose disease are in red).

The models predict satisfactorily the experimental pressure-stretch data (Fig. 3 upper panel). Fig. 4 illustrates computed $F_{\text {red }}^{\text {mod }}$, which in all cases satisfied $\left|F_{\text {red }}^{\text {mod }}\right|<1 \mu \mathrm{N}$. However, the predicted axial stretch, shown in Fig. 3 (bottom panel), corresponds to the experiments only to a limited extent.

Computed intramural distributions of the circumferential and axial stress for donor M60a for $P=2.3 \mathrm{kPa}$ (representative venous pressure) and $P=13.3 \mathrm{kPa}$ (representative arterial pressure) are depicted in Fig. 5 with indicated numerical values of the intramural stress gradient $\left(S R_{k}^{P}\right)$. 
Veselý J., Horný L., Chlup H., Adámek T., Krajiček M., Žitný R. (2015) Constitutive Modeling of Human saphenous veins at overloading Pressures. Journal of the Mechanical Behavior of Biomedical Materials, in press. DOI: 10.1016/j.jmbbm.2015.01.023 Publisher link http://dx.doi.org/10.1016/j.jmbbm.2015.01.023

\section{Discussion}

In our study, overloading inflation-extension tests were performed with 15 human saphenous veins. The experiments were conducted with free axial extension of the tubes without axial pre-stretch. This approach was chosen in order to simulate conditions after implantation of the graft in arterial system. The experimental data were fitted by the hyperelastic nonlinear anisotropic constitutive model proposed by Holzapfel et al. (2000). Only the passive mechanical response was modeled.

Fig. 3 shows that veins under simultaneous inflation and extension exhibit significantly smaller deformations in axial direction than in circumferential direction. It may be a consequence of approximately two-times smaller stresses in axial than in circumferential direction, as it is shown in Fig. 5 for donor M60a ( $\alpha=0^{\circ}$, black curves). This finding is in agreement with results of Wesly et al. (1975), who studied the pressure-strain relationship of dog jugular and human saphenous veins. Specifically, in our study measured axial stretches are generally in the range from 0.98 to 1.03 . For samples M50, M63a, F49, M60a, F69, F66V, M60d and M63b, the range of axial deformation during the entire pressurization period was not higher than approx. 1\%. This small deformation is, however, determined with relatively high measurement uncertainty. In the worst case, the resolution of the digital images was 19 pixels/mm (M76). In this case, the reference distance of the longitudinal marks was 104 pixels. Thus to obtain axial extension of $1 \%$, it would be necessary to find marks at a distance of 105.04 pixels. This is a change of 1 pixel. Due to this fact axial stretches in the interval from 0.99 to 1.01 are affected by experimental uncertainty which is in Fig. 3 highlighted by gray lines. In this case, we decided to present in Fig. 3 predictions of the simulation based on (7) and (8) with substituted (3) in which $\lambda_{\alpha}\left(r_{o}\right)$ and $\lambda_{z}$ were also based on the model rather than solely predicting $P$ at the experimentally obtained stretches, which may be affected by measurement error. This approach, however, gives somewhat different $\lambda_{z}$ than was measured experimentally.

Four donors with diagnosed varicose disease were included in this study in order to reveal differences in mechanical response in comparison with healthy donors. However, we were able to obtain only four samples which is a small number for statistical evaluation and these samples do not 
Veselý J., Horný L., Chlup H., Adámek T., Krajíček M., Žitný R. (2015) Constitutive Modeling of Human saphenous veins at overloading Pressures. Journal of the Mechanical Behavior of Biomedical Materials, in press. DOI: 10.1016/j.jmbbm.2015.01.023 Publisher link http://dx.doi.org/10.1016/j.jmbbm.2015.01.023

appear to behave differently. Finally, we preserved them in the study, because obtained material parameters could be used by other authors.

In our study, it was assumed that veins are in stress-free configuration in their cylindrical geometry. This is the most important limitation of our study, since it is well known that for instance arteries exhibit residual stresses. Artery rings cut radially spring open to release these stresses; this is the socalled opening angle method (Chuong and Fung 1986, Rachev and Greenwald 2002, Holzapfel et al., 2000). Zhao et al. (2007) examined the biomechanical properties of human saphenous veins at supraphysiologic pressures using the distension experiment and were able to measure the zero-stress state of vein tissue by radially cutting open their specimens. They observed the residual opening angle around $120^{\circ}$. Similar results (opening angle from $90^{\circ}$ to $130^{\circ}$ ) were obtained by Huang and Yen (1998) for human pulmonary vein segments with diameter comparable to saphenous veins. We also tried to measure the residual strain by the opening angle, but it was impossible with our current technical equipment. The vein walls were so compliant that they collapsed and we could not distinguish between forces imposed by handling and forces induced by the releasing residual stress.

However, to provide at least some qualified estimate of how large the residual stress in the venous wall could be, the intramural distribution of the circumferential and axial stress in one representative case (donor M60a) was computed for opening angles $\alpha=0^{\circ}, \alpha=10^{\circ}, \alpha=20^{\circ}, \alpha=30^{\circ}, \alpha=40^{\circ}$ and $\alpha=$ $50^{\circ}$. The computations were provided for pressure $P=2.3 \mathrm{kPa}$ (representative venous pressure) and for $P=13.3 \mathrm{kPa}$ (representative arterial pressure), which is close to the pressure in great saphenous vein in standing position (approx. $12 \mathrm{kPa}$ ) measured by Pollack and Wood (1949) and Neglén and Raju (2000). The results (Fig. 5) suggest that the optimal opening angle (homogenizing the stress distribution across the wall thickness - uniform stress or strain hypothesis; Chuong and Fung, 1986; Takamizawa and Hayashi, 1987) could be expected about $40^{\circ}$. Our results of the opening angle simulations showed that we should anticipate value higher than $0^{\circ}$. However, one can find higher values in observations of Zhao et al. (2007). It is clear that the uniform stress or strain hypothesis for saphenous veins should be addressed in future research and proven experimentally. The results also 
Veselý J., Horný L., Chlup H., Adámek T., Krajíček M., Žitný R. (2015) Constitutive Modeling of Human saphenous veins at overloading Pressures. Journal of the Mechanical Behavior of Biomedical Materials, in press. DOI: 10.1016/j.jmbbm.2015.01.023 Publisher link http://dx.doi.org/10.1016/j.jmbbm.2015.01.023

indicate that under arterial conditions the inner radius of the vein wall could be highly overloaded. This is consistent with the development of intimal hyperplasia after a graft surgery.

To the best of our knowledge, this is the first study witch presents a comprehensive set of material parameters for human saphenous veins modeled as the thick wall tube suitable for describing multiaxial stress states. They can be helpful as input in numerical simulations of the remodeling and adaptation processes triggered after bypass surgery involving autologous vein grafts (Hwang et al., 2012, 2013; Sassani et al., 2013).

\section{Acknowledgement}

This study has been supported by Czech Ministry of Health grant no. NT 13302 .

\section{References}

Ballyk, P.D., Walsh, C., Butany, J., Ojha, M., 1998. Compliance mismatch may promote graft-artery intimal hyperplasia by altering suture-line stresses. Journal of Biomechanics 31, 229-237.

Cacho, F., Doblaré, M., Holzapfel, G.A., 2007. A procedure to simulate coronary artery bypass graft surgery. Medical and Biological Engineering and Computing 45, 819-827.

Canver, C.C., 1995. Conduit options in coronary artery bypass surgery. Chest 108, 1150-1155.

Chuong, C.J., Fung, Y.C., 1986. On residual stresses in arteries. Journal of Biomechanical Engineering 108, 189192.

Desch, G. W. Weizsäcker, H. W., 2007. A model for passive elastic properties of rat vena cava. Journal of Biomechanics 40, 3130-3145.

Donovan, D.L., Schmidt, S.P., Townshend, S.P., Njus, G.O., Sharp, W.V., 1990. Material and structural characterization of human saphenous vein. Journal of Vascular Surgery 12, 531-537.

Eberth, J. F. Cardamone, L., Humphrey, J. D., 2011. Evolving biaxial mechanical properties of mouse carotid arteries in hypertension. Journal of Biomechanics 44, 2532-2537. 
Veselý J., Horný L., Chlup H., Adámek T., Krajíček M., Žitný R. (2015) Constitutive Modeling of Human saphenous veins at overloading Pressures. Journal of the Mechanical Behavior of Biomedical Materials, in press. DOI: 10.1016/j.jmbbm.2015.01.023 Publisher link http://dx.doi.org/10.1016/j.jmbbm.2015.01.023

FitzGibbon, G. M., Kafka, H. P., Leach, A. J., Keon, W. J., Hooper, G. D., Burton, J. R., 1996. Coronary bypass graft fate and patient outcome: Angiographic follow-up of 5,065 grafts related to survival and reoperation in 1,388 patients during 25 years. Journal of the American College of Cardiology 28, 616-626.

Holzapfel, G.A., Gasser, T.C., Ogden, R.W., 2000. A new constitutive framework for arterial wall mechanics and a comparative study of material models. Journal of Elasticity 61, 1-48.

Holzapfel, G. A., 2006. Determination of material models for arterial walls from uniaxial extension tests and histological structure. Journal of Theoretical Biology 238, 290-302.

Horný, L., Netušil, M., Voňavková, T., 2014a. Axial prestretch and circumferential distensibility in biomechanics of abdominal aorta. Biomechanics and Modeling in Mechanobiology 13, 783-799.

Horny, L., Netusil, M., Daniel, M., 2014b. Limiting extensibility constitutive model with distributed fibre orientations and ageing of abdominal aorta. Journal of the Mechanical Behavior of Biomedical Materials 38, 3951.

Huang, W., Yen, R.T., 1998. Zero-stress states of human pulmonary arteries and veins. Journal of Applied Physiology 85, 867-873.

Humphrey, J. D., Eberth, J. F., Dye, W. W., Gleason, R. L., 2009. Fundamental role of axial stress in compensatory adaptations by arteries. Journal of Biomechanics 42, 1-8.

Hwang, M., Berceli, S. A., Garbey, M., Kim, N. H., Tran-Son-Tay, R., 2012. The dynamics of vein graft remodeling induced by hemodynamic forces: A mathematical model. Biomechanics and Modeling in Mechanobiology, 11, 411-423.

Hwang, M., Garbey, M., Berceli, S. A., Wu, R., Jiang, Z., Tran-Son-Tay, R., 2013. Rule-based model of vein graft remodeling. PLoS ONE 8, e57822.

Matsumoto, T., Hayashi, K., 1996. Stress and strain distribution in hypertensive and normotensive rat aorta considering residual strain. Journal of Biomechanical Engineering 118, 62-71.

McGilvray, K. C., Sarkar, R., Nguyen, K., Puttlitz, C. M., 2010. A biomechanical analysis of venous tissue in its normal and post-phlebitic conditions. Journal of Biomechanics 43, 2941-2947. 
Veselý J., Horný L., Chlup H., Adámek T., Krajíček M., Žitný R. (2015) Constitutive Modeling of Human saphenous veins at overloading Pressures. Journal of the Mechanical Behavior of Biomedical Materials, in press. DOI: 10.1016/j.jmbbm.2015.01.023 Publisher link http://dx.doi.org/10.1016/j.jmbbm.2015.01.023

Neglén, P., Raju, S., 2000. Differences in pressures of the popliteal, long saphenous, and dorsal foot veins. Journal of Vascular Surgery 32, 894-901.

Perera, G.B., Mueller, M.P., Kubaska, S.M., Wilson, S.E., Lawrence, P.F., Fujitani, R.M., 2004. Superiority of Autogenous Arteriovenous Hemodialysis Access: Maintenance of Function with Fewer Secondary Interventions. Annals of Vascular Surgery 18, 66-73.

Pollack, A.A., Wood, E.H., 1949. Venous pressure in the saphenous vein at the ankle in man during exercise and changes in posture. Journal of applied physiology 1, 649-662.

Rachev, A., Greenwald, S.E., 2002. Residual strains in conduit arteries. Journal of Biomechanics 36, 661-670.

Sassani, S. G., Theofani, A., Tsangaris, S., Sokolis, D. P., 2013. Time-course of venous wall biomechanical adaptation in pressure and flow-overload: Assessment by a microstructure-based material model. Journal of Biomechanics 46, 2451-2462.

Sokolis, D. P., 2013. Experimental investigation and constitutive modeling of the 3D histomechanical properties of vein tissue. Biomechanics and Modeling in Mechanobiology 12, 431-451.

Stooker, W., Gök, M., Sipkema, P., Niessen, H.W.M., Baidoshvili, A., Westerhof, N., Jansen, E.K., Wildevuur, C.R.H., Eijsman, L. , 2003. Pressure-Diameter Relationship in the Human Greater Saphenous Vein. Annals of Thoracic Surgery 76, 1533-1538.

Takamizawa, K., Hayashi, K., 1987. Strain energy density function and uniform strain hypothesis for arterial mechanics. Journal of Biomechanics 20, 7-17.

Tran-Son-Tay, R., Hwang, M., Garbey, M., Jiang, Z., Ozaki, C. K., Berceli, S. A., 2008. An experiment-based model of vein graft remodeling induced by shear stress. Annals of Biomedical Engineering 36, 1083-1091.

Wesly, R.L.R., Vaishnav, R.N., Fuchs et, a.J.C.A., Patel, D.J., Greenfield Jr., J.C., 1975. Static linear and nonlinear elastic properties of normal and arterialized venous tissue in dog and man. Circulation Research 37 , 509-520.

Zhao, J., Jesper Andreasen, J., Yang, J., Steen Rasmussen, B., Liao, D., Gregersen, H., 2007. Manual pressure distension of the human saphenous vein changes its biomechanical properties - implications for coronary artery bypass grafting. Journal of Biomechanics 40, 2268-2276. 
Veselý J., Horný L., Chlup H., Adámek T., Krajičck M., Žitný R. (2015) Constitutive Modeling of Human saphenous veins at overloading Pressures. Journal of the Mechanical Behavior of Biomedical Materials, in press. DOI: 10.1016/j.jmbbm.2015.01.023 Publisher link http://dx.doi.org/10.1016/j.jmbbm.2015.01.023

A

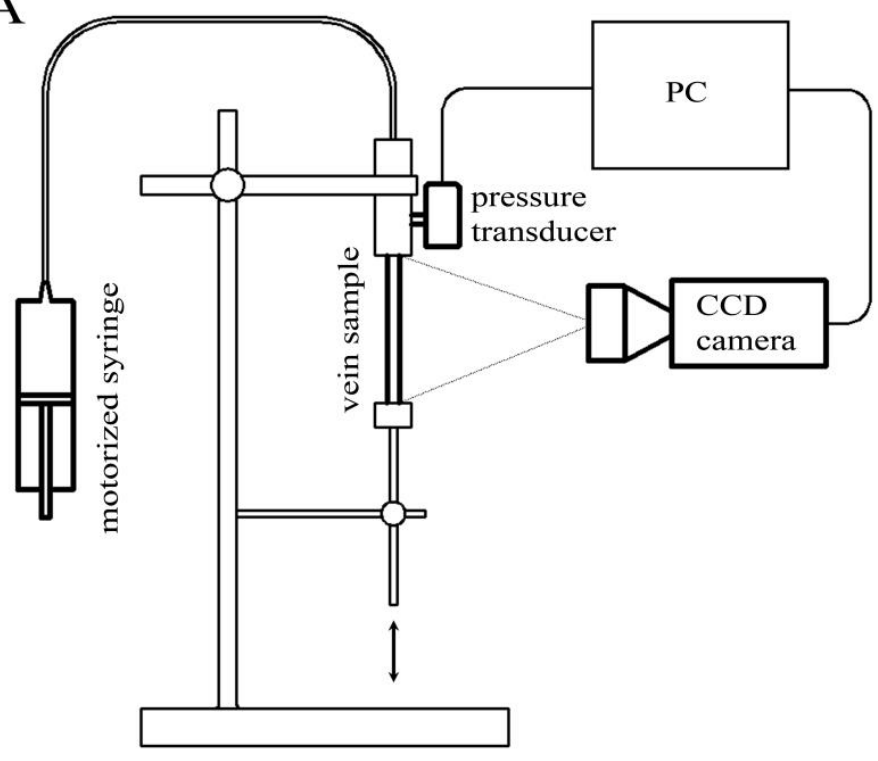

B

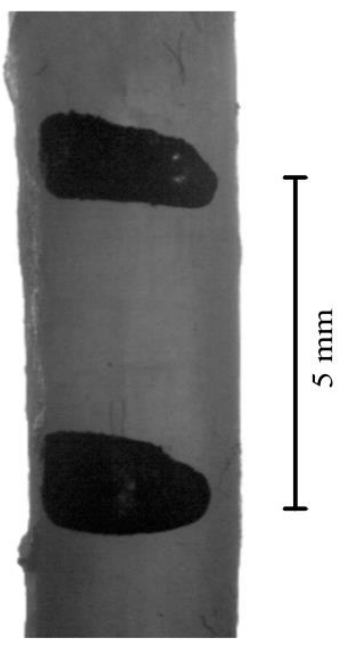

Fig. 1. Experimental inflation-extension test set-up (panel A), and a picture of the sample taken with a CCD camera (panel B). The black marks were used to identify the longitudinal deformation of the vein. 
Veselý J., Horný L., Chlup H., Adámek T., Krajiček M., Žitný R. (2015) Constitutive Modeling of Human saphenous veins at overloading Pressures. Journal of the Mechanical Behavior of Biomedical Materials, in press. DOI: 10.1016/j.jmbbm.2015.01.023 Publisher link http://dx.doi.org/10.1016/j.jmbbm.2015.01.023
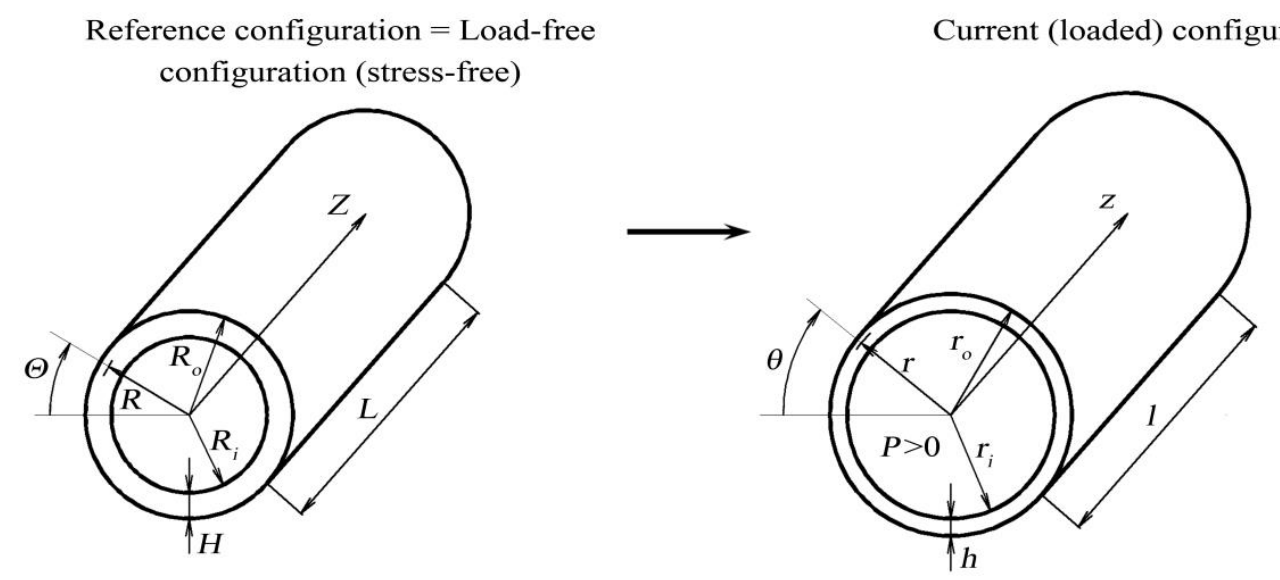

Fig. 2. Kinematics of the deformation of the vein wall. The stress-free configuration (assumed to be the same as the load-free configuration) and the deformed current (loaded) configuration are depicted. 
Veselý J., Horný L., Chlup H., Adámek T., Krajičck M., Žitný R. (2015) Constitutive Modeling of Human saphenous veins at overloading Pressures. Journal of the Mechanical Behavior of Biomedical Materials, in press. DOI: 10.1016/j.jmbbm.2015.01.023 Publisher link http://dx.doi.org/10.1016/j.jmbbm.2015.01.023

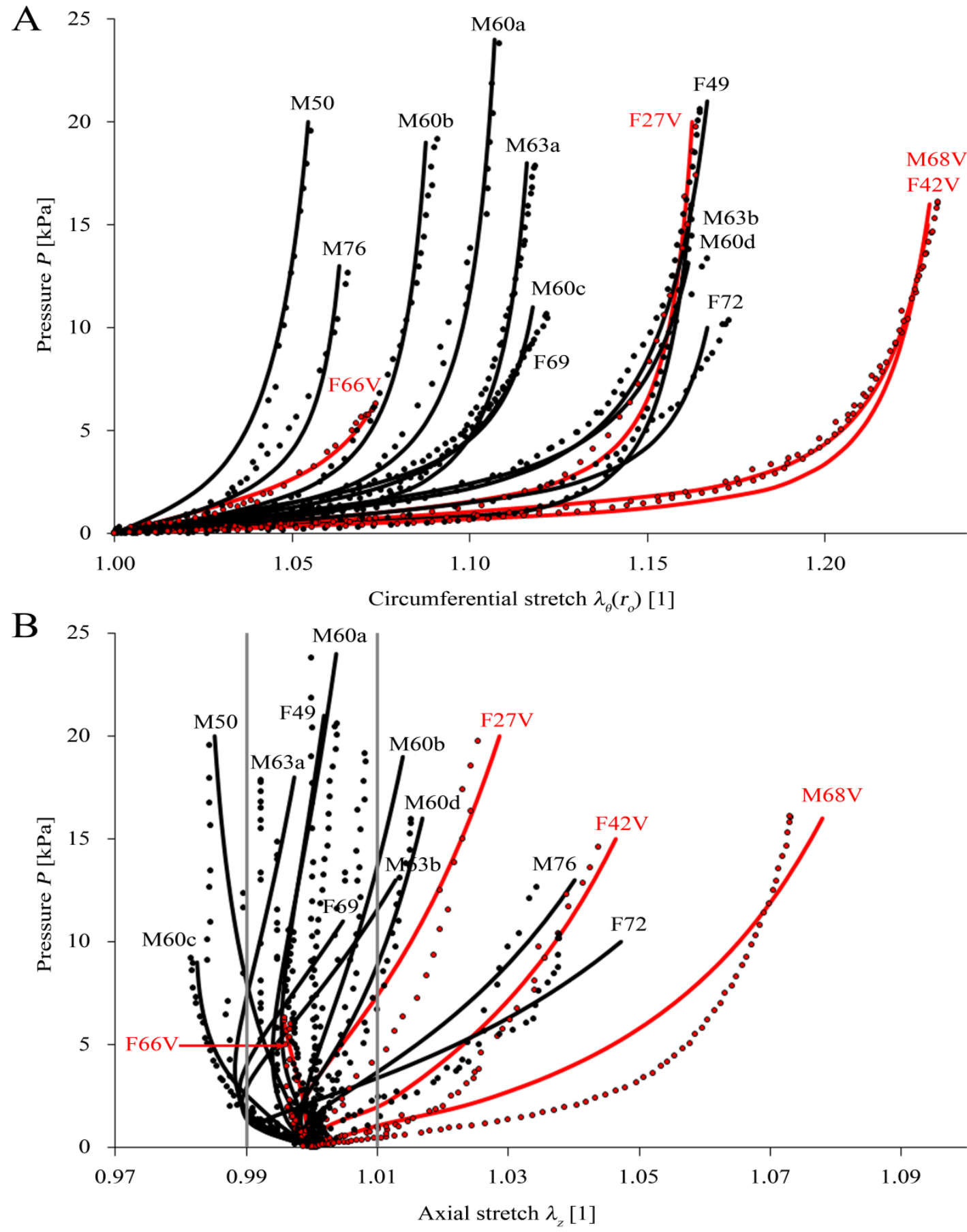

Fig. 3. The resulting pressure-circumferential stretch at the outer radius (panel A) and pressure-axial stretch (panel B) dependences. The experimental data (dotted curves) are compared with data predicted by the constitutive model (solid curves). The donors with varicose disease are in red. The interval in axial stretch from 0.99 to 1.01 in panel B identified by gray lines represents bounds of uncertainty caused by resolution of digital cameras. 
Veselý J., Horný L., Chlup H., Adámek T., Krajičck M., Žitný R. (2015) Constitutive Modeling of Human saphenous veins at overloading Pressures. Journal of the Mechanical Behavior of Biomedical Materials, in press. DOI: 10.1016/j.jmbbm.2015.01.023 Publisher link http://dx.doi.org/10.1016/j.jmbbm.2015.01.023

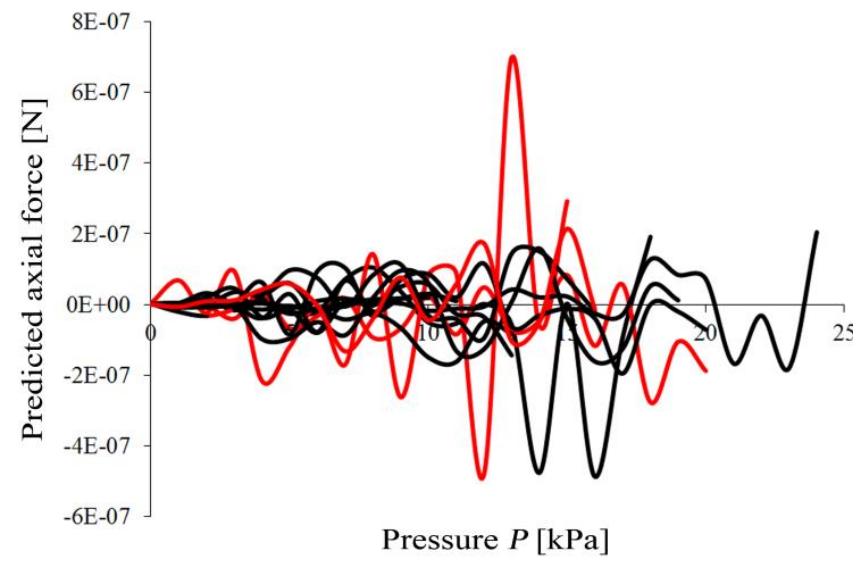

Fig. 4. The computed reduced axial force-pressure curves showing the zero axial force condition. Red color is used for donors with varicose disease. 
Veselý J., Horný L., Chlup H., Adámek T., Krajíček M., Žitný R. (2015) Constitutive Modeling of Human saphenous veins at overloading Pressures. Journal of the Mechanical Behavior of Biomedical Materials, in press. DOI: 10.1016/j.jmbbm.2015.01.023 Publisher link http://dx.doi.org/10.1016/j.jmbbm.2015.01.023
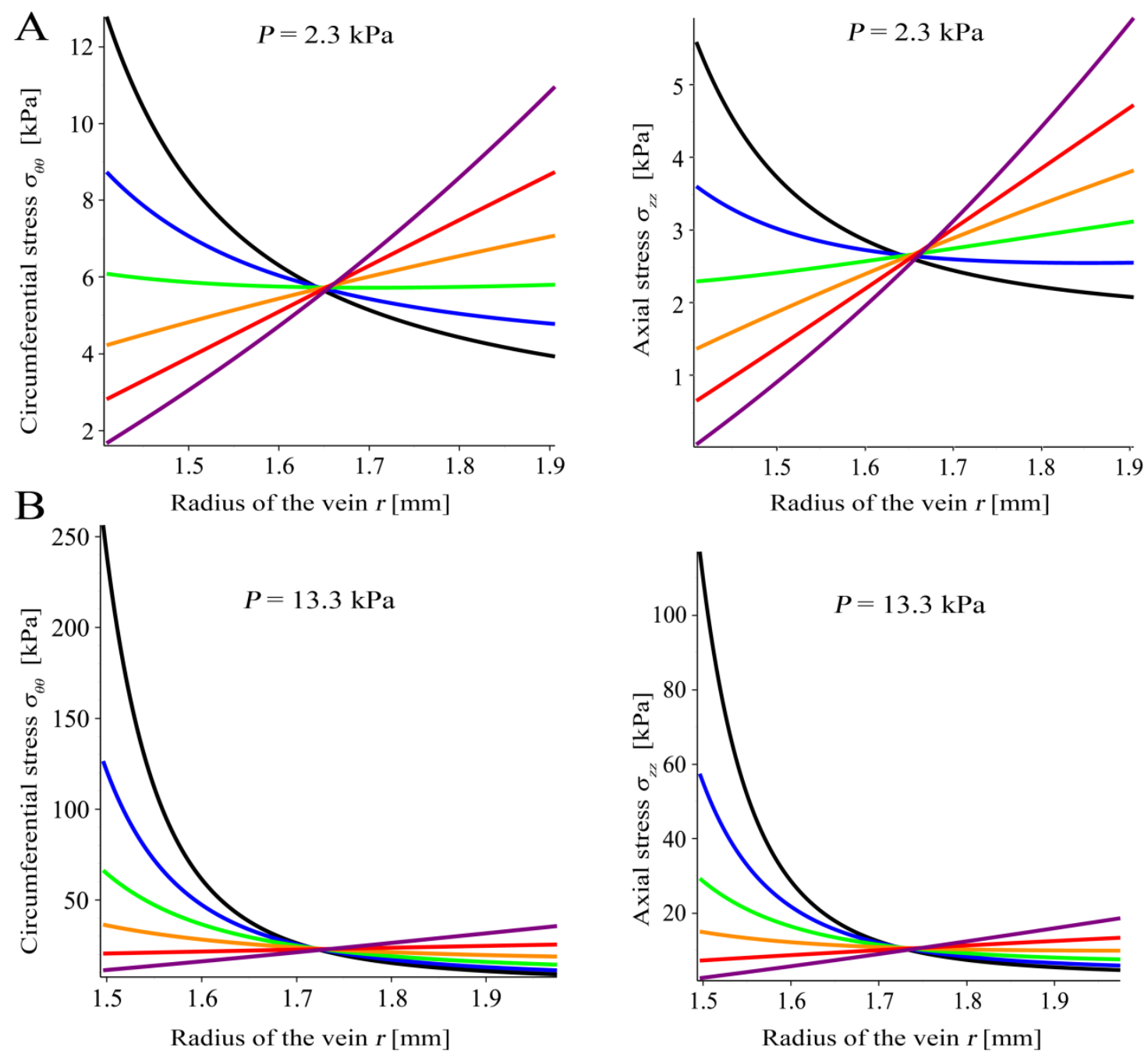

\begin{tabular}{ccccccc} 
& & & & & & \\
\cline { 2 - 7 } & $\alpha=0^{\circ}$ & $\alpha=10^{\circ}$ & $\alpha=20^{\circ}$ & $\alpha=30^{\circ}$ & $\alpha=40^{\circ}$ & $\overline{\alpha=50^{\circ}}$ \\
\hline$S R_{\theta}^{2.3 k P a}$ & 3.25 & 1.83 & 1.05 & 0.60 & 0.32 & 0.15 \\
$S R_{z}^{2.3 k P a}$ & 2.68 & 1.41 & 0.74 & 0.36 & 0.14 & 0.01 \\
\hline$S R_{\theta}^{13.3 k P a}$ & 28.55 & 11.27 & 4.62 & 1.94 & 0.80 & 0.32 \\
$S R_{z}^{13.3 k P a}$ & 24.85 & 9.71 & 3.87 & 1.52 & 0.54 & 0.14
\end{tabular}

Fig. 5. The simulation of the influence of opening angle $\alpha$ for donor M60a. The circumferential and axial stress gradient through the vein wall for transmural pressure $2.3 \mathrm{kPa}$ (panel A) and for $13.3 \mathrm{kPa}$ (panel B). Panel C displays stress gradients through the wall thickness. 
Veselý J., Horný L., Chlup H., Adámek T., Krajičck M., Žitný R. (2015) Constitutive Modeling of Human saphenous veins at overloading Pressures. Journal of the Mechanical Behavior of Biomedical Materials, in press. DOI: 10.1016/j.jmbbm.2015.01.023 Publisher link http://dx.doi.org/10.1016/j.jmbbm.2015.01.023

Table 1. Age and sex of the donors (F stands for female and $\mathrm{M}$ for male), obtained material parameters $\left(\mu, k_{1}, k_{2}, \beta\right)$, normalized root mean square error $\operatorname{RMSE}(P)$ and computed mean force during pressurization $\operatorname{Mean}\left(\left|F_{\text {red }}^{\text {mod }}\right|\right)$ for each sample of vein.

\begin{tabular}{|c|c|c|c|c|c|c|c|c|c|c|c|}
\hline \multirow[b]{2}{*}{ Donor } & \multirow[b]{2}{*}{$\begin{array}{c}\text { Age } \\
\text { [years] }\end{array}$} & \multirow[b]{2}{*}{ Sex } & \multirow[b]{2}{*}{$\begin{array}{c}R_{o} \\
{[\mathrm{~mm}]}\end{array}$} & \multirow[b]{2}{*}{$\begin{array}{c}H \\
{[\mathrm{~mm}]}\end{array}$} & \multicolumn{4}{|c|}{ Material parameters } & \multirow{2}{*}{$\begin{array}{c}\text { RMSE }(P) \\
{[-]}\end{array}$} & \multirow{2}{*}{$\begin{array}{c}\operatorname{Mean}\left(\left|F_{\text {red }}{ }^{\text {mod }}\right|\right) \\
{[\mathrm{N}]}\end{array}$} & \multirow[b]{2}{*}{ Pathology } \\
\hline & & & & & $\left.\begin{array}{c}\mu \\
{[\mathrm{kPa}]}\end{array}\right]$ & $\begin{array}{c}k_{1} \\
{[\mathrm{kPa}]}\end{array}$ & $\begin{array}{l}k_{2} \\
{[-]}\end{array}$ & $\begin{array}{c}\beta \\
{\left[{ }^{\circ}\right]}\end{array}$ & & & \\
\hline \multicolumn{12}{|l|}{ CABG } \\
\hline \multirow[t]{5}{*}{$\mathrm{a}$} & 63 & M & 2.89 & 0.83 & 5.5 & 4.0 & 61.7 & 40.3 & 0.082 & $9.1 \mathrm{E}-08$ & - \\
\hline & 66 & $\mathrm{~F}$ & 2.12 & 0.49 & 28.4 & 8.4 & 122.1 & 39.3 & 0.072 & $2.6 \mathrm{E}-08$ & varicose \\
\hline & 27 & F & 2.32 & 0.88 & 4.0 & 1.5 & 18.2 & 43.0 & 0.046 & 7.0E-08 & varicose \\
\hline & 42 & $\mathrm{~F}$ & 2.78 & 0.80 & 5.7 & 1.4 & 13.5 & 43.1 & 0.046 & $1.8 \mathrm{E}-07$ & varicose \\
\hline & 69 & M & 1.14 & 0.59 & 4.2 & 3.0 & 10.8 & 44.1 & 0.069 & 8.7E-09 & - \\
\hline $\mathrm{b}$ & 63 & M & 2.05 & 0.76 & 5.6 & 4.5 & 13.6 & 42.7 & 0.030 & $4.5 \mathrm{E}-08$ & - \\
\hline \multirow[t]{3}{*}{$\mathrm{a}$} & 60 & M & 1.80 & 0.53 & 9.9 & 5.9 & 62.2 & 39.8 & 0.077 & 4.4E-08 & - \\
\hline & 76 & M & 1.98 & 0.57 & 7.0 & 19.3 & 48.2 & 36.5 & 0.021 & $3.8 \mathrm{E}-08$ & - \\
\hline & 50 & M & 2.33 & 0.57 & 30.7 & 30.3 & 330 & 38.4 & 0.090 & $5.5 \mathrm{E}-08$ & - \\
\hline \multirow[t]{2}{*}{ b } & 60 & M & 1.92 & 0.47 & 13.7 & 9.3 & 85.5 & 38.2 & 0.041 & 6.7E-08 & - \\
\hline & 49 & $\mathrm{~F}$ & 1.86 & 0.39 & 14.1 & 4.2 & 43.2 & 41.2 & 0.037 & $2.9 \mathrm{E}-08$ & - \\
\hline Mean & 55 & - & 2.11 & 0.62 & 11.7 & 8.3 & 73.6 & 40.6 & 0.055 & $5.9 \mathrm{E}-08$ & - \\
\hline SD & 15 & - & 0.48 & 0.16 & 9.1 & 8.4 & 87.5 & 2.3 & 0.023 & $4.5 \mathrm{E}-08$ & - \\
\hline \multicolumn{12}{|l|}{ Autopsy } \\
\hline & 72 & $\mathrm{~F}$ & 1.78 & 0.71 & 3.1 & 2.3 & 8.8 & 42.6 & 0.045 & $2.5 \mathrm{E}-08$ & - \\
\hline $\mathrm{c}$ & 60 & M & 0.92 & 0.28 & 9.5 & 5.0 & 53.5 & 41.5 & 0.062 & 6.4E-09 & - \\
\hline \multirow[t]{2}{*}{ d } & 60 & M & 2.14 & 0.42 & 4.4 & 1.4 & 50.5 & 40.4 & 0.044 & $5.9 \mathrm{E}-08$ & - \\
\hline & 68 & M & 1.80 & 0.48 & 4.2 & 1.0 & 13.1 & 41.9 & 0.027 & $6.1 \mathrm{E}-08$ & varicose \\
\hline Mean & 65 & - & 1.66 & 0.47 & 5.3 & 2.5 & 31.5 & 41.6 & 0.044 & $3.8 \mathrm{E}-08$ & - \\
\hline SD & 5 & - & 0.52 & 0.18 & 2.5 & 1.6 & 20.6 & 0.8 & 0.014 & 2.7E-08 & - \\
\hline
\end{tabular}

